\title{
Mega-Environment Concept in Agriculture: A Review
}

\author{
Debdali Chowdhury*, Anshu Bharadwaj and V.K. Sehgal \\ Indian Agricultural Research Institute, Pusa campus, New-Delhi 110012, India \\ *Corresponding author
}

\begin{tabular}{|l|}
\hline Ke y w o r d s \\
Mega-environment, \\
Agriculture, \\
$\begin{array}{l}\text { Homogeneous, } \\
\text { Genotype-by- } \\
\text { environment } \\
\text { interactions }\end{array}$ \\
\hline Article Info \\
\hline $\begin{array}{l}\text { Accepted: } \\
\text { 14 December } 2018 \\
\text { Available Online: } \\
\text { 10 January } 2019\end{array}$ \\
\hline
\end{tabular}

Greater emphasis on future constraints to agricultural production is motivated by the projections of environmental change. The speed of population, change in climate and environmental has pressurized the crop community to understand the importance of those stresses which may result in the significant declines in yield. Advances in data availability, advance information technology, and new and improved methods to target genotypes to environments have benefited the crop improvement practices. No methodology is found in literature which integrates factors like climate, soil, land cover etc., and can predict the most suitable environment (Area) for growing maize based on its genetic variability. Megaenvironment can be defined as a part, which may not necessarily be contiguous, of growing region of any species of a particular crop, with homogeneous environment which encourages similar genotypes to perform best. The MEs (homogeneous environments of production delineated on the basis of an agroclimatic) are helpful to the crop breeders in managing the genotype-byenvironment interactions and then extrapolate the same within similar agro climatic areas. In this paper several research works are reviewed to provide emphasis on the Mega-Environment concept for crop improvement.

\section{Introduction}

Agriculture, for decades, had been associated with the production of basic food crops. About $70 \%$ of Indian population is directly engaged in agriculture. Greater emphasis on future constraints to agricultural production is motivated by the projections of environmental change. The speed of population, change in climate and environmental has pressurized the crop community to understand the importance of those stresses which may result in the significant declines in yield. Advances in data availability, advance information technology, and new and improved methods to target genotypes to environments have benefited the crop improvement practices. So, the scientists and the researchers are giving effort to integrate soil, land use land cover and other social and environmental factors altogether 
and to map the most suitable MegaEnvironment (MEs) for a particular crop (based on their genetic variability) for the betterment of the crop yield and also to combat the rapid climate change. The aim of this paper is to give a review on the MegaEnvironment concept which is the new hope for the crop scientists and researchers to fight against the climate change by increasing the crop yield (Rajaram, 1993).

In earlier days, new crop varieties were produced by the centres of the Consultative Group on International Agricultural Research (CGIAR), they trained the farmers to use those varieties and then got the seeds from the practice and popularised those varieties. When the crop improvement program started it required a huge fund. So, the use of spatial maps, models and computer techniques help to boost up the efficiency of their development and cultivar testing which became an economic approach. Spatial analysis for the dissemination program and cultivar testing helps to target the genotype to environments. Now, the question is how the breeders can use the spatial tools to find where they should go for the varietal trial? For this scenario the Mega -Environment (MEs) approach is introduced.

\section{What is mega-environment?}

The term Mega-Environment is first coined by CIMMYT, 1989. Mega-environment can be defined as a part, which may not necessarily be contiguous, of growing region of any species of a particular crop, with homogeneous environment which encourages similar genotypes to perform best. The MEs (homogeneous environments of production delineated on the basis of an agro-climatic) are helpful to the crop breeders in managing the genotype-by-environment interactions (GEI) and then extrapolate the same within similar agro climatic areas. To formulate the operational decisions considering the environmental factors for the phenotypic expression, nature and magnitude of existing genotype environment interactions (GEI) (Boyd et al., 1976) are the most important consideration for the plant breeders before identifying the trial locations. The MEs help to maximize the crop yield in spite of having a heterogeneous growing region, despite differences in cultivar rankings from place to place due to genotype-environment interactions. So, it becomes necessary to subdivide the whole growing region into several relatively homogeneous megaenvironments and to breed and target adapted genotypes for each mega-environment.

\section{Criteria of Mega-Environment (MEs)}

To identify mega-environments the statistical strategies (Boyd et al., 1976) should meet certain criteria:

1. There should be flexibility with various designs of experiments in handling several yield trials

2. Fraction of the total variation which is relevant to identify the mega-environments should be focused mainly

3. Duality in giving integrated information on both genotypes and environments

4. Primary objective should be relevant one to show which genotypes suitable where

\section{Previous research work}

Balancing the inputs and outputs on a farm is fundamental to its success and profitability. The ability of GIS to analyse and visualize agricultural environments and workflows has proved to be very beneficial to those involved in the farming industry. From mobile GIS in the field to the scientific analysis of production data at the farm manager's office, GIS is playing an increasing role in agriculture production throughout the world 
by helping farmers increase production, reduce costs, and manage their land more efficiently. While natural inputs in farming cannot be controlled, they can be better understood and managed with GIS applications such as crop yield estimates, soil amendment analyses, and erosion identification and remediation (ESRI, 2009).

At present, Mega-Environment (MEs) approach has been applied for many fields (Agriculture and allied sectors) in India as well as in abroad. The CIMMYT started its Maize Program, 35 years back by developing germplasm for maize production environments by efficiently allocating resources to particular needs and problems. This task divided the maize production regions of the world in different major ecologies and by the end of 1980s, these ecologies were subdivided into 30 areas in 70 countries, which were called megaenvironments (MEs). In 1980s CIMMYT defined a set of global maize production environment which is known as megaenvironment for improving the target germplasm. This publication presents a revision of maize that draws on GIS.

Hugh. et al., (1997) discussed about how to identify the relevant criteria for evaluating mega-environment analyses and the application of the Additive Main Effects and Multiplicative Interaction (AMMI) model to mega-environment analysis.

Hartkamp et al., (2000) presented a GISbased approach which revised definitions of global maize production environments, called "mega-environments" (MEs), which CIMMYT and its partners were using. On the climate data, that represented a four-month growing season, for the major locations where maize is produced locations, cluster analysis was performed. The onset of the growing season was determined on the basis of the month when the ratio of precipitation over potential evapotranspiration exceeded 0.5 ; this was with assumption of rainfed production. Diagnostic Criteria for mapping MEs were diagnosed on the basis of results of cluster analysis and expert knowledge. The maps generated as the results can be used for selecting appropriate target environments for maize germplasm and trials. They can also be used in setting the priorities selecting the site for global maize breeding programs.

Laura Palomeque et al., (2009) researched on how to use a population which is derived from a cross between an adapted and an exotic elite line for the understanding of the genetic causes underlying the adaptation to two mega-environments (China and Canada).

Hodson and White (2010) reviewed the use GIS and crop models for predicting impacts of climate change and examining options for adaptation. Increasingly, downscaled outputs from a range of global general circulation models under differing future scenarios are used as key inputs for both tools. Examples are given for major food crops and key agricultural zones, with a bias towards tropical and subtropical regions. Consideration is also given to factors limiting efficient application of the tools to climate change research. Both technologies will see increasing use in climate change research and in applications of research in decision making. Credible studies of crop responses to climate involve dealing with large sets of data and potentially millions of simulations, especially if adaptation is considered. While the computational challenges are daunting, the greater challenge is how to devise efficient protocols for selecting the most meaningful scenarios, interpreting the results and summarizing outputs for decision makers.

Glenn Hyman et al., (2013) reviewed the usage of spatial analysis that can support 
research in crop improvement which aimed at matching genotypes to their most appropriate environmental niches. Specifically in the highly variable drought-prone environments of southern Africa and for maize crop, statistical techniques were applied to the multilocation yield trial data. They were combined with environmental factors which were drawn from GIS (Setimela et al., 2003, 2005; Maideni, 2006). Regional trials were divided into seven groups using cluster analysis. They had with seasonal maximum temperature, precipitation, soil $\mathrm{pH}$, and nitrogen stress identified as the factors accounting for repeatable GEI. Finally, six mega-environment zones were found on the basis of seasonal maximum temperature and precipitation, since the soil $\mathrm{pH}$ data available was not reliable for inclusion.

CIMMYT has defined 12 MEs for wheat which includes global wheat cultivating regions. Twelve Mega-Environments (ME) involving global wheat areas are defined. Wheat Program conducted by CIMMYT mainly focusing on 10 such MEs and has accordingly structured its breeding program to address the respective germplasm needs. Six Mega-Environments are dedicated to Spring Wheat: ME (Irrigated), ME (High Rainfall), ME (Acid Soils), ME (Low Rainfall), ME (High Temperature) and ME (High Latitude). Three Mega-Environments are assigned to Facultative Wheat: ME (Irrigated), ME (High Rainfall) and ME (Semi-Arid). Additionally, three MEs belong to the Winter Wheat: ME10 (Irrigated), ME (High Rainfall) and ME12 (Semi-Arid).

A new graphical approach for conducting mega-environment analysis and test location evaluation which utilizes unbalanced multiyear variety trial data is presented by Yan, W. (2015). It consists of three steps: (i) generating a $\mathrm{G}$ (genotypic main effect) plus GE (genotype $\times$ environment interaction), or
GGE, biplot using a missing-value estimation procedure and treating each location-year combination (trial) as an environment; (ii) summarizing the interrelations among test locations (L) in a GGL + GGE biplot, which is the same GGE biplot imposed with the test locations. The placement of a test location in the biplot is defined by the coordinates of all environments at the location; and (iii) summarizing any sub-region (S) (i.e., megaenvironment) differentiation revealed in Step 2 in a GGS biplot, which is the same GGE biplot imposed with the sub-regions.

Kumar and Babu (2016) discussed the success of planning for developmental activities depend on the quality and quantity of information available on both natural and socio-economic resources. It is, therefore, essential to devise the ways and means of organizing computerized information system. These systems must be capable of handling vast amount of data collected by modern techniques and produce up to date information. Remote sensing technology has already demonstrated its capabilities to provide information on natural resources such as crop, land use, soils, forest etc., on regular basis.

The role of remote sensing and GIS in agricultural applications can be broadly categorized into two groupsinventorying/mapping and management. While remote sensing data alone are mostly used for, inventorying, crop acreage estimation, crop condition assessment, crop yield forecasting, soil mapping, etc., purposes, the management related activities like irrigation management, cropping system analysis, precision farming, etc., needs various other types of spatial physical environmental information. The latter has to be integrated with remote sensing data, where the functionality of GIS will be used. In the present study, techniques of remote sensing 
and Geographic Information System (GIS) have been used to monitor and map the Sugarcane crop at farm level. The Quick bird data of $60 \mathrm{~cm}$ resolution was acquired and was geometrically corrected and georeferenced for subsequent processing and analysis using Digital Image Processing (DIP) and GIS. After the generation of the thematic layers at farm level using GIS, using the various customization tolls available in the GIS a web based monitoring system for the sugarcane has been prepared. This monitoring system helps the decision makers to take appropriate decisions in order to increase the crop production and other activities related to the crop. The Web GIS helps the nontechnical users to access the information and take appropriate measures to improve the crop production. These user-friendly systems need to be developed and made simple in order to take the technology from the scientific community to the common man.

Hao Gong et al., (2017) described an Internetbased GIS platform termed as MEGA-WEB. The interface was designed considering the urban planning and management challenges in developing countries of Asia and Africa due to the limited availability of effective tools, and proficiency and data resources in data analysis.

In conclusion, based on the review on very limited literature available so far, scope to carry out research work has been explored. After identifying the homogeneous MegaEnvironments for a particular crop in a particular region, breeding and targeting the adapted genotypes for each MEs using GIS technologies can be carried out. Identification of Mega-Environments and genotypes for those crops which can adapt to certain specific stresses (biotic or abiotic) are also can be taken into consideration for future research work.

\section{References}

Smith, M. E., Mihm, J. A., and Jewell, D. C. (1989). Breeding for multiple resistance to temperate, subtropical, and tropical maize insect pests at CIMMYT. In International Symposium on Methodologies for Developing Host Plant Resistance to Maize Insects. Mexico, DF (Mexico). 9-14 Mar 1987.

Edmeades, G. O. (1989). An account of how priorities are set among mega environments from a breeding perspective (No. 17). CIMMYT working paper Document.

CIMMYT. 1989b. An account of how priorities are set among mega environments from a breeding perspective. Internal document Number 17. Mexico D.F.: CIMMYT

Boyd, B. (1990). Corporate linkages and organizational environment: A test of the resource dependence model. Strategic management journal, 11(6), 419-430.

Rajaram, S., Van Ginkel, M., and Fischer, R. A. (1993, July). CIMMYT's wheat breeding mega-environments (ME). In Proceedings of the 8th International wheat genetic symposium, Pp. 11011106.

Gauch, Hugh, and Richard W. Zobel (1997).Identifying mega-environments and targeting genotypes. Crop science. 37(2), 311-326

Yan, W., Hunt, L. A., Sheng, Q, Szlavnics, Z (2000). Cultivar evaluation and megaenvironment investigation based on the GGE biplot. Crop Science, 40(3), 597605.

Hartkamp, A. D. (2001). Maize production environments revisited: a GIS-based approach. CIMMYT.

Padgham, J. (2009). Agricultural Development under a Changing Climate. 
Gong, H., Simwanda, M., and Murayama, Y. (2017). An Internet-Based GIS Platform Providing Data for Visualization and Spatial Analysis of Urbanization in Major Asian and African Cities. ISPRS International Journal of GeoInformation, 6(8), 257.

Hodson, D., and White, J. (2010). GIS and crop simulation modelling applications in climate change research. Climate change and crop production. Wallingford, UK: CABI Publishers, 245-262.
Hyman, G., Hodson, D., and Jones, P. (2013). Spatial analysis to support geographic targeting of genotypes to environments. Frontiers in physiology, 4, 40

Yan, W. (2015). Mega-environment analysis and test location evaluation based on unbalanced multiyear data. Crop Science, 55(1), 113-122.

Kumar and Babu (2016). A Web GIS Based Decision Support System for Agriculture Crop Monitoring System-A Case Study from Part of Medak District. Journal of Remote Sensing \& GIS.

\section{How to cite this article:}

Debdali Chowdhury, Anshu Bharadwaj and Sehgal, V.K. 2019. Mega-Environment Concept in Agriculture: A Review. Int.J.Curr.Microbiol.App.Sci. 8(01): 2147-2152. doi: https://doi.org/10.20546/ijcmas.2019.801.224 